\title{
Deadenylation is a widespread effect of miRNA regulation
}

\author{
ANA EULALIO, ${ }^{1,2}$ ERIC HUNTZINGER, ${ }^{1,2}$ TADASHI NISHIHARA, ${ }^{1}$ JAN REHWINKEL, ${ }^{1,3}$ \\ MARIA FAUSER, ${ }^{1}$ and ELISA IZAURRALDE ${ }^{\mathbf{1}}$ \\ ${ }^{1}$ Max Planck Institute for Developmental Biology, D-72076 Tübingen, Germany
}

\begin{abstract}
miRNAs silence gene expression by repressing translation and/or by promoting mRNA decay. In animal cells, degradation of partially complementary miRNA targets occurs via deadenylation by the CAF1-CCR4-NOT1 deadenylase complex, followed by decapping and subsequent exonucleolytic digestion. To determine how generally miRNAs trigger deadenylation, we compared mRNA expression profiles in D. melanogaster cells depleted of AGO1, CAF1, or NOT1. We show that $\sim 60 \%$ of AGO1 targets are regulated by CAF1 and/or NOT1, indicating that deadenylation is a widespread effect of miRNA regulation. However, neither a poly(A) tail nor mRNA circularization are required for silencing, because mRNAs whose 3 ' ends are generated by a self-cleaving ribozyme are also silenced in vivo. We show further that miRNAs trigger mRNA degradation, even when binding by $40 \mathrm{~S}$ ribosomal subunits is inhibited in cis. These results indicate that miRNAs promote mRNA decay by altering mRNP composition and/or conformation, rather than by directly interfering with the binding and function of ribosomal subunits.
\end{abstract}

Keywords: Argonaute; deadenylation; decapping; GW182; miRNAs; mRNA decay; silencing; translational repression

\section{INTRODUCTION}

MicroRNAs are genome-encoded $\sim 22$-nucleotide (nt)-long RNAs that regulate gene expression in a broad range of biological processes including development, cellular differentiation, fat metabolism, and growth control. The regulatory functions of miRNAs are mediated by the Argonaute family of proteins, which assemble with miRNAs into miRNA-induced silencing complexes (miRISCs). Within these complexes, miRNAs guide the Argonaute proteins to fully or partially complementary mRNA targets, which are then silenced post-transcriptionally (for review, see Bushati and Cohen 2007; Nilsen 2007; Eulalio et al. 2008a).

Initial studies suggested that animal miRNAs repress translation without significantly affecting the abundance of target mRNAs (Lee et al. 1993; Wightman et al. 1993; Moss et al. 1997; Olsen and Ambros 1999). More recently, however, studies in Caenorhabditis elegans, zebrafish embryos, Drosophila melanogaster, and human cells have shown that miRNAs can also induce significant mRNA

\footnotetext{
${ }^{2}$ These authors contributed equally to this work.

${ }^{3}$ Present address: Cancer Research UK London Research Institute, Lincoln's Inn Fields 44, London WC2A 3PX, United Kingdom.

Reprint requests to: Elisa Izaurralde, Max Planck Institute for Developmental Biology, Spemannstrasse 35, D-72076 Tübingen, Germany; e-mail: elisa.izaurralde@tuebingen.mpg.de; fax: 49-7071-601-1353.

Article published online ahead of print. Article and publication date are at http://www.rnajournal.org/cgi/doi/10.1261/rna.1399509.
}

degradation (Bagga et al. 2005; Krützfeldt et al. 2005; Wu and Belasco 2005; Behm-Ansmant et al. 2006a,b; Giraldez et al. 2006; Mishima et al. 2006; Wu et al. 2006; Chendrimada et al. 2007; Eulalio et al. 2007, 2008b; Baek et al. 2008; Selbach et al. 2008). In agreement with these observations, the levels of predicted and validated miRNA targets increase in cells in which the miRNA pathway is inhibited (for example, by depleting Dicer or Argonaute proteins) (Behm-Ansmant et al. 2006a,b; Giraldez et al. 2006; Rehwinkel et al. 2006; Schmitter et al. 2006; Eulalio et al. 2007). Conversely, overexpressing miRNAs in cells in which they are normally not expressed down-regulates transcripts containing complementary binding sites (Lim et al. 2005; Baek et al. 2008; Selbach et al. 2008).

In animal cells, Argonaute proteins usually do not degrade target mRNAs through endonucleolytic cleavage (except when the miRNA is fully complementary to the target), but rather direct mRNAs to the general mRNA degradation machinery. This observation is supported by studies showing that miRNAs accelerate deadenylation and decapping of their targets (Behm-Ansmant et al. 2006a,b; Giraldez et al. 2006; Mishima et al. 2006; Wu et al. 2006; Eulalio et al. 2007).

miRNA-mediated mRNA decay requires several components: a member of the Argonaute protein family, the Pbody component GW182, the CAF1-CCR4-NOT deadenylase complex, the decapping enzyme DCP2, and several decapping activators including DCP1, Ge-1, EDC3, and RCK/p54 
(also known as Me31B) (Rehwinkel et al. 2005; BehmAnsmant et al. 2006a,b; Eulalio et al. 2007, 2008b). Current evidence indicates that GW182 interacts with the Argonaute proteins directly, which recruit it to the miRNAtargets (Ding et al. 2005; Jakymiw et al. 2005; Liu et al. 2005; Meister et al. 2005; Rehwinkel et al. 2005; BehmAnsmant et al. 2006a,b; Chu and Rana 2006; El-Shami et al. 2007; Till et al. 2007; Zhang et al. 2007; Eulalio et al. 2008b). This interaction between Argonaute proteins and GW182 leads to the (direct or indirect) recruitment of the deadenylase and decapping complexes, and is required both for the translational repression and mRNA degradation triggered by miRNAs (Ding et al. 2005; Jakymiw et al. 2005; Liu et al. 2005; Meister et al. 2005; Behm-Ansmant et al. 2006a,b; Chu and Rana 2006; Eulalio et al. 2007; 2008b; Till et al. 2007; Zhang et al. 2007).

To determine whether deadenylation is a general feature of miRNA-mediated silencing, we compared mRNA expression profiles in D. melanogaster cells depleted of AGO1, CAF1, or NOT1. We show that about $60 \%$ of AGO1 targets are also regulated by CAF1 and/or NOT1, demonstrating that deadenylation is a widespread effect of miRNA regulation. However, deadenylation per se is not required for silencing, because miRNAs could efficiently down-regulate the expression of mRNAs containing $3^{\prime}$ ends that were generated by ribozyme cleavage. We also show that miRNAs can trigger deadenylation and subsequent mRNA degradation of mRNAs whose association with $40 \mathrm{~S}$ ribosomal subunits is prevented in cis. Thus, even for mRNAs that are not being actively translated, miRNAs can still increase the accessibility of general mRNA degradation enzymes to the mRNA $5^{\prime}$ cap structure and the poly(A) tail. We propose that miRNAs down-regulate gene expression by altering mRNP composition and/or conformation, thereby reducing both translation efficiency and mRNA levels independently.

\section{RESULTS}

\section{Deadenylation is a widespread effect of miRNA regulation}

To determine what fraction of miRNA targets are deadenylated, we compared mRNA expression profiles in cells depleted of either AGO1 or components of the CAF1CCR4-NOT deadenylase complex. In particular, we depleted CAF1 or NOT1, because earlier studies in $D$. melanogaster Schneider (S2) cells showed depleting these proteins strongly inhibits deadenylation (S2 cells) (Temme et al. 2004; Behm-Ansmant et al. 2006a,b). For each protein tested, we obtained expression profiles from two or three independent RNA samples. As a reference, RNA samples were isolated from cells treated with a dsRNA targeting GFP (green fluorescent protein).

We grouped detectable transcripts into three classes, depending on their expression levels relative to control cells. These were under-represented transcripts (at least 1.5fold under-represented compared with the reference sample) (Fig. 1A-F, blue), transcripts that did not significantly change $(<1.5$-fold different from the reference) (Fig. 1A-F,

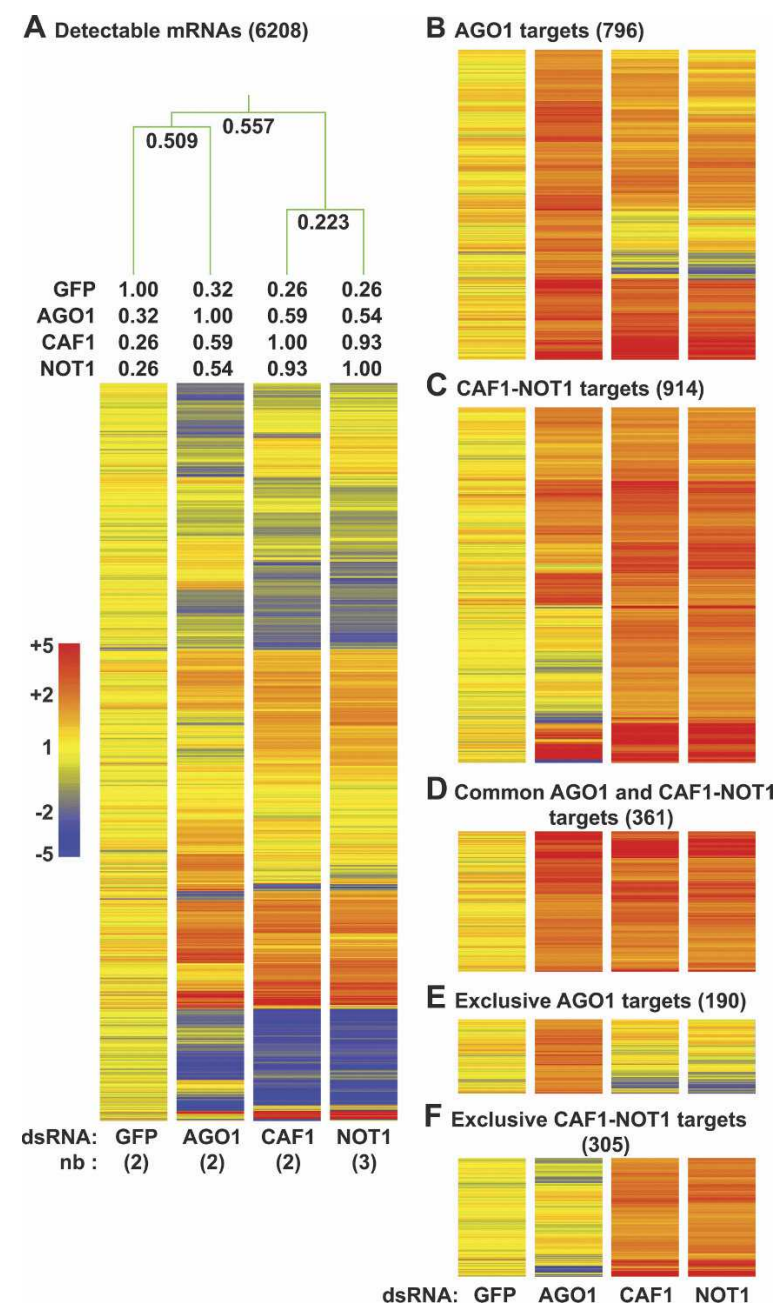

FIGURE 1. Expression profiles of D. melanogaster S2 cells depleted of AGO1, CAF1, or NOT1. (A) S2 cells were treated with the dsRNAs indicated below the lanes. The number (nb) of independent expression profiles obtained per depleted protein is indicated in brackets. The average expression levels of transcripts detectable in all profiles (6208 mRNAs) are shown. RNAs are represented as lines colored relative to their expression levels, as indicated on the left. Numbers above the lanes indicate rank correlation coefficients relative to AGO1, CAF1, or NOT1. The experiment tree was calculated using the distance option in the GeneSpring software (Euclidean distance). (B) RNAs at least 1.5-fold overrepresented in the two independent profiles obtained for AGO1. (C) RNAs at least 1.5-fold overrepresented in at least four of five profiles obtained for CAF1 and NOT1. (D) RNAs at least 1.5-fold overrepresented in the two independent profiles obtained for AGO1 and in at least four of five profiles obtained for CAF1 and NOT1. (E) RNAs at least 1.5fold overrepresented in the two independent profiles obtained for AGO and $<1.5$-fold up-regulated in at least four of five profiles obtained for CAF1 and NOT1. $(F)$ RNAs at least 1.5-fold overrepresented in at least four of five profiles obtained for CAF1 and NOT1 and $<1.5$-fold upregulated in the two profiles obtained for AGO1. The number of mRNAs displayed per panel is indicated in brackets. Note that the lines representing individual mRNAs are compressed in $A$. 
yellow), and overrepresented transcripts (at least 1.5-fold overrepresented) (Fig. 1A-F, red). We only considered transcripts that fell into the same class in the two independent profiles obtained for AGO1 and CAF1 and in the three independent profiles obtained for NOT1. For selected mRNAs, we validated changes in transcript levels by Northern blotting (data not shown).

The expression profiles for cells depleted of CAF1 or NOT1 correlated well with each other (rank correlation coefficient $r=0.93$ ) (Fig. 1A), as expected for subunits of a multimeric protein complex. Both of these profiles also correlated with profiles of AGO1-depleted cells (Fig. 1A). The rank correlation coefficients between AGO1 and CAF1 or AGO1 and NOT1 profiles were $r=0.59$ or $r=0.54$, respectively (for comparison, the rank correlation coefficient between the profiles of cells depleted of AGO1 or Drosha is $r \geq 0.7$ ) (Rehwinkel et al. 2006). These results indicate that AGO1, CAF1, and NOT1 regulate common targets. Transcripts up-regulated in AGO1-depleted cells are enriched for predicted and validated miRNA targets (Behm-Ansmant et al. 2006a,b; Rehwinkel et al. 2006; Eulalio et al. 2007), so we next focused on these transcripts.

The similarity between the expression profiles from cells depleted of AGO1, CAF1, or NOT1 is illustrated by the observation that out of 796 transcripts overrepresented in the AGO1 knockdown, $60 \%$ were also overrepresented in the profiles obtained for CAF1 and/or NOT1, and $45 \%$ were commonly regulated by both CAF1 and NOT1 (Fig. 1B-D; Supplemental Table I). The probability that this would happen by chance is $P=2.6 \mathrm{E}-115$. Transcripts regulated by both AGO1 and the deadenylase complex have longer $3^{\prime}$ UTRs on average and are significantly enriched for predicted targets of several miRNAs (Supplemental Tables I, II), as reported for AGO1 targets (Rehwinkel et al. 2006).

We also observed important differences between the profiles of cells depleted of AGO1, CAF1, or NOT1. Of the 914 transcripts up-regulated in cells depleted of CAF1 and NOT1, 33\% remained unchanged or were downregulated in the AGO1 profiles (Fig. 1C,F; Supplemental Table II). This indicates that CAF1 and NOT1 regulate a significant number of transcripts that are not miRNA targets, consistent with the role of these proteins in degradation of bulk mRNA.

We also noted that $24 \%$ (190 transcripts) of mRNAs upregulated in cells depleted of AGO1 remained unchanged (or were down-regulated) in four out of five profiles obtained for CAF1 and NOT1 (Fig. 1B,E; Supplemental Table I). Nevertheless, we could not detect significant differences between these transcripts and those commonly regulated by AGO1, CAF1, and NOT1 in the average 3 ' UTR length or the number of predicted miRNA-binding sites.

One possible explanation for the existence of AGO1 targets that are not regulated by the deadenylase complex is that miRNAs trigger mRNA degradation independently of deadenylation. Alternatively, in depleted cells, the residual levels of CAF1 or NOT1 may be sufficient to sustain deadenylation of a subset of mRNAs. We favor this second explanation because Axs is among the AGO1 targets unaffected in cells depleted of CAF1 or NOT1, although deadenylation of this previously characterized target is brought about by the cognate miRNA (Behm-Ansmant et al. 2006a). In summary, by comparing gene expression profiles in cells depleted of AGO1 or components of the deadenylase complex, we estimate that at least $60 \%$ of transcripts up-regulated in AGO1-depleted cells are normally degraded through deadenylation.

\section{miRNAs destabilize target mRNAs via deadenylation and subsequent decapping}

To validate the array data, 3' UTRs of transcripts upregulated by AGO1, NOT1, and CAF1 were cloned downstream of the firefly luciferase (F-Luc) open reading frame. In particular, we constructed reporters containing the $3^{\prime}$ UTRs of three uncharacterized genes: CG9441 (a predicted target of miR-1) and CG1856 and CG12024 (both predicted targets of miR-92a). Cotransfecting these reporters with the corresponding miRNAs reduced both luciferase activity and mRNA abundance, compared with the values measured in the absence of the miRNA (Fig. 2A-F).

We have shown previously that miRNAs trigger deadenylation, which is followed by decapping and subsequent exonucleolytic digestion of the mRNA body (Behm-Ansmant et al. 2006a,b; Eulalio et al. 2007). Consequently, when decapping is inhibited, deadenylated mRNA decay intermediates accumulate; in denaturing agarose gels, these deadenylated mRNAs exhibit a higher electrophoretic mobility than those that are polyadenylated (Behm-Ansmant et al. 2006a,b; Eulalio et al. 2007). Therefore, to investigate whether our reporters were deadenylated, we assayed for the accumulation of deadenylated decay intermediates in cells where decapping was inhibited by codepleting the decapping activators Ge-1 and Me31B (Eulalio et al. 2007).

To do this, control cells or cells codepleted of Ge-1 and Me31B were transfected with a mixture of three plasmids: one expressing the miRNA reporters, another expressing miRNA primary transcripts or the corresponding empty vector, and a third expressing Renilla luciferase (R-Luc). In all experiments described below we compensated for differences in transfection efficiencies by normalizing the firefly luciferase activity and mRNA levels to those of the Renilla luciferase. To compensate for potential nonspecific effects of the depletions on general protein synthesis or mRNA levels, the normalized values of firefly luciferase activity and mRNA levels in the presence of the miRNA were divided by those obtained in the absence of the miRNA for each knockdown.

Our results showed codepleting Ge-1 and Me31B inhibited miRNA-mediated mRNA degradation, although 


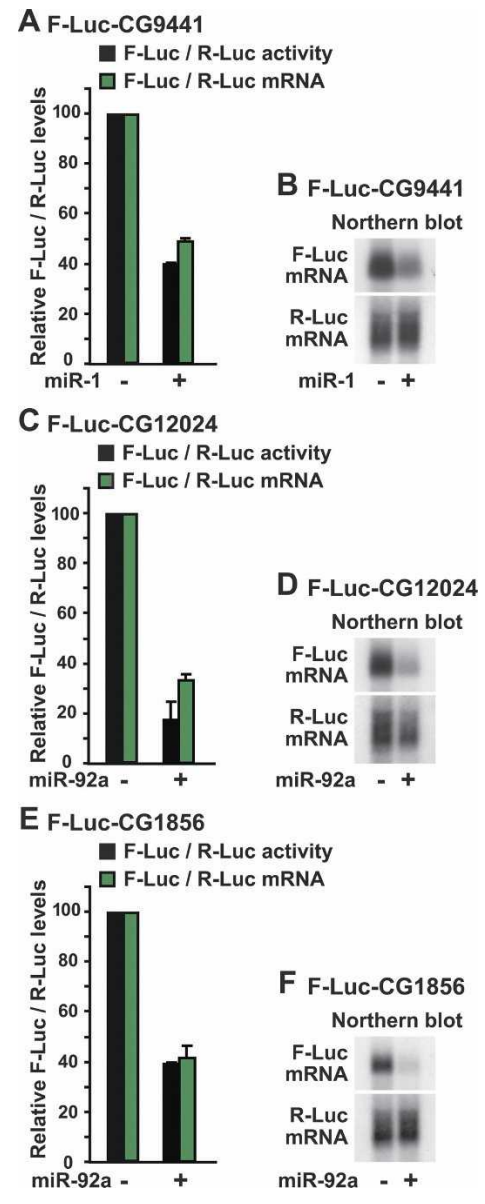

FIGURE 2. Validation of the array data. $(A-F)$ S2 cells were transfected with a mixture of three plasmids: one expressing a firefly luciferase (F-Luc) transcript, followed by the indicated 3' UTRs; another expressing the miRNA primary transcripts (+miRNA) or the corresponding empty vector (-); and a third expressing Renilla luciferase (R-Luc). Firefly luciferase activity (black bars) and mRNA levels (green bars) were normalized to that of the Renilla luciferase. The normalized values of F-Luc activity and mRNA levels were set to 100 in cells transfected with the empty vector (i.e., in the absence of the miRNAs). Mean values \pm standard deviations from three independent experiments are shown. $(B, D, F)$ Northern blot analysis of representative RNA samples shown in $A, C$, and $E$, respectively.

luciferase activity was not always restored to control levels (Fig. 3A,B). Moreover, the accumulated transcripts migrated slightly faster, suggesting that they were deadenylated (Fig. 3C,E, cf. lanes 6 and lanes 5). To confirm this assumption, RNA samples isolated from cells codepleted of $\mathrm{Ge}-1$ and $\mathrm{Me} 31 \mathrm{~B}$ were treated with RNase $\mathrm{H}$ in the presence or absence of oligo(dT). In cells not expressing the miRNA, both the F-Luc reporter and an endogenous mRNA (rp49, encoding ribosomal protein L32, which served as an internal control) migrated faster after oligo(dT)-directed RNase $\mathrm{H}$ cleavage had removed the poly(A)-tail (Fig. 3D,F, cf. lanes 2 and lanes 1). This indicates that in the absence of the miRNA, the reporters were polyadenylated.
In contrast, in the presence of the miRNA, the mobility of the F-Luc reporter mRNA did not change after oligo(dT)-directed RNase $\mathrm{H}$ cleavage, while that of the rp49 mRNA did (Fig. 3D,F, cf. lanes 4 and lanes 3). Thus, the presence of the miRNAs caused deadenylation of the F-Luc reporters. Because deadenylated mRNAs are expected to be translated less efficiently, this may explain
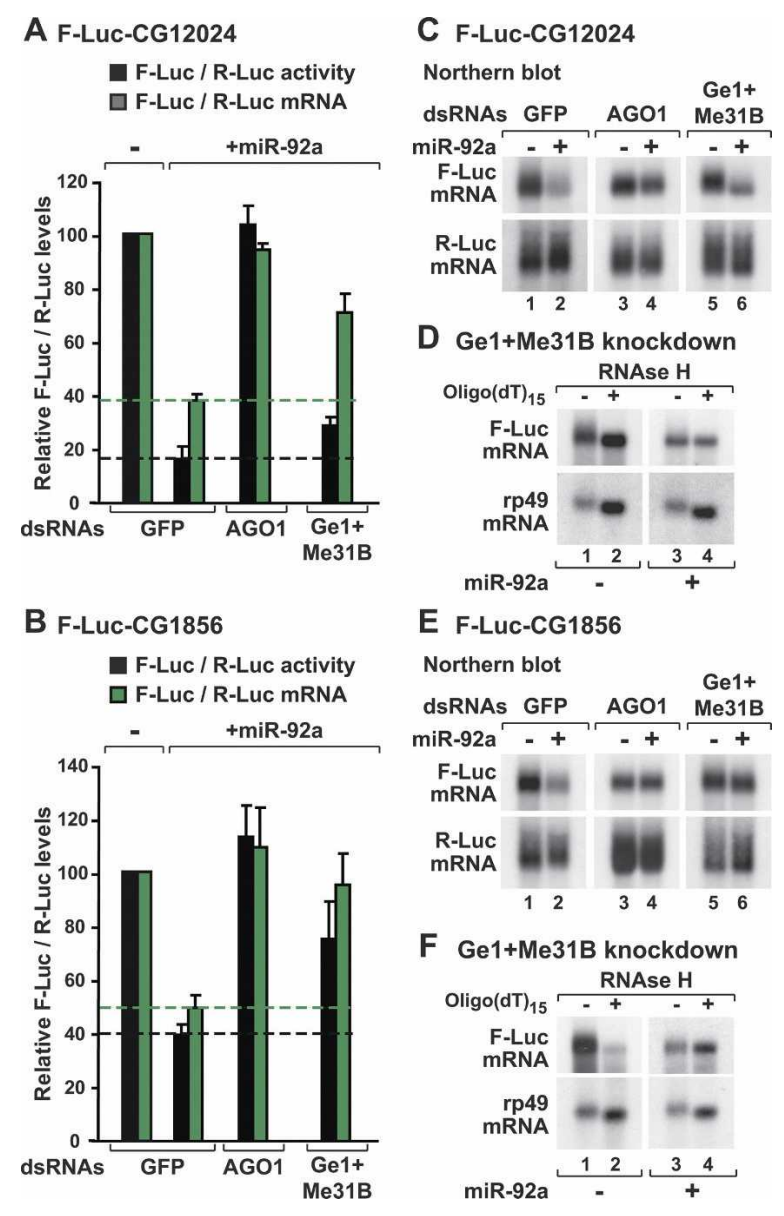

FIGURE 3. miRNAs trigger deadenylation-dependent decapping. $(A-F)$ S2 cells were treated with the indicated dsRNAs on days 0 and 4 . On day 6 , cells were cotransfected with a mixture of three plasmids: one expressing a Firefly luciferase (F-Luc) transcript containing the indicated $3^{\prime}$ UTRs, another expressing the miR-92a primary transcript $(+)$ or the corresponding empty vector $(-)$, and a third expressing Renilla luciferase (R-Luc). Firefly luciferase activity and mRNA levels were normalized to that of the Renilla luciferase. For each knockdown, the normalized values of F-Luc activity and mRNA levels were set to 100 in cells transfected with the empty vector, i.e., in the absence of the miRNA (data not shown except for control cells treated with GFP dsRNA). Black and green dashed lines indicate FLuc activity and mRNA levels, respectively, in the presence of the miRNAs in control cells. Mean values \pm standard deviations from three independent experiments are shown. (C,E) Northern blot analysis of representative RNA samples shown in $A$ and $B$, respectively. $(D, F)$ The RNA samples corresponding to the Ge-1 and Me31B knockdowns shown in $C$ and $E$ were treated with RNase $\mathrm{H}$ in the absence or presence of oligo(dT) and analyzed by Northern blot. The endogenous rp49 mRNA served as a positive control for RNase $\mathrm{H}$ treatment. 
why restoring mRNA levels by codepleting Ge-1 and $\mathrm{Me} 31 \mathrm{~B}$ does not correspondingly increase firefly luciferase activity (e.g., Fig. 3A; Behm-Ansmant et al. 2006a,b). As a positive control, depleting AGO1 restored both F-Luc activity and mRNA levels, as reported before (Fig. 3AC,E; Rehwinkel et al. 2005; Behm-Ansmant et al. 2006a,b; Eulalio et al. 2008b).

The observations described above, together with previous reports (Behm-Ansmant et al. 2006a,b; Giraldez et al. 2006; Mishima et al. 2006; Wu et al. 2006; Eulalio et al. 2007), provide compelling evidence that miRNAs destabilize target mRNAs via deadenylation and subsequent decapping.

\section{Neither mRNA circularization nor a poly(A)-tail are required for miRNA regulation}

The above results and additional studies show that miRNAs elicit the deadenylation and decay of target mRNAs; however, whether deadenylation is required for silencing is a matter of controversy. Indeed, previous studies addressing this question led to opposite conclusions. In $D$. melanogaster and human cells, mRNAs without a poly(A) tail or with a histone $3^{\prime}$-terminal stem-loop (HSL) could be silenced (Pillai et al. 2005; Wu et al. 2006; Eulalio et al. 2008b), suggesting that deadenylation is not required for silencing. In contrast, other studies showed that in transfected human cells or cell-free extracts, mRNAs lacking a poly(A) tail were partially or fully refractory to silencing, respectively (Humphreys et al. 2005; Wang et al. 2006; Wakiyama et al. 2007).

The results obtained with reporters ending in a histone 3 '-terminal stem-loop may differ from those obtained with reporters lacking a poly $(\mathrm{A})$ tail, because the histone stem-loop structure may promote mRNA circularization through interactions between the histone stem-loop-binding protein (HLBP or SLBP) and translation initiation factors bound to the mRNA $5^{\prime}$ cap structure (Ling et al. 2002; Gorgoni et al. 2005). Circularization is unlikely for the reporters lacking a poly(A) tail. If the primary effect of miRNAs was to interfere with mRNA circularization, then mRNAs with a histone $3^{\prime}$ stem-loop should be regulated, whereas those lacking a poly(A) tail should be immune to silencing.

We therefore investigated whether miRNAs can regulate mRNAs whose $3^{\prime}$ ends are generated by ribozyme cleavage (and are unlikely to circularize). To this end, we replaced the cleavage and polyadenylation signal of miRNA-regulated reporters by a self-cleaving hammerhead ribozyme (HhR) (Fig. 4). We selected the F-Luc-CG5281 and F-Luc-CG7709 reporters because they have short 3' UTRs (300 and 228 nt in length, respectively); this reduces the probability that cryptic polyadenylation sites will be activated, as observed for reporters having longer $3^{\prime}$ UTRs (data not shown).

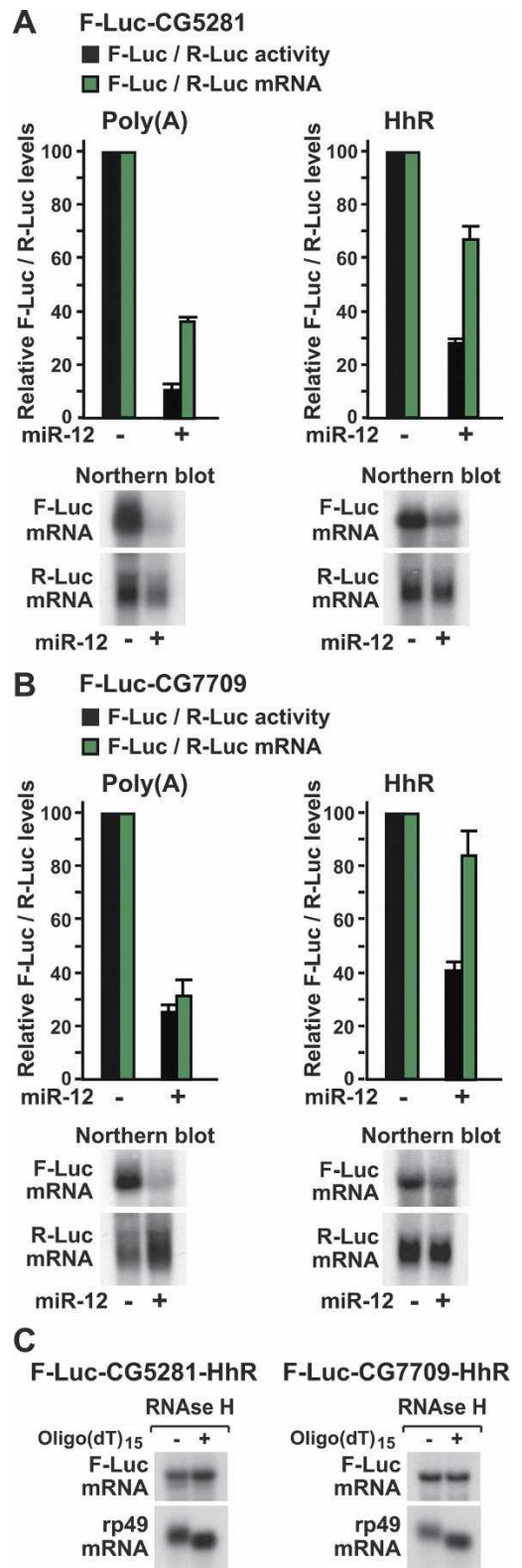

FIGURE 4. Deadenylation is not required for silencing. $(A, B) \mathrm{S} 2$ cells were transfected with F-Luc reporters ending with a $3^{\prime}$ poly $(A)$ tail or a self-cleavable ribozyme (HhR), as indicated. The transfection mixture included either a plasmid expressing the miR-12 primary transcript $(+)$ or the corresponding empty vector $(-)$. A plasmid expressing Renilla luciferase (R-Luc) served as a transfection control. Firefly luciferase activity and mRNA levels were analyzed as described in Figure 2. Northern blot analysis of representative RNA samples is shown below the corresponding graphs. (C) RNA samples corresponding to the HhR reporters were treated with RNase $\mathrm{H}$ in the absence or presence of oligo $(\mathrm{dT})$ and analyzed by Northern blot. The endogenous rp49 mRNA served as a positive control for the RNase $\mathrm{H}$ treatment.

When we normalized F-Luc activity with the corresponding mRNA levels in the absence of miRNAs, mRNAs carrying a self-cleavable ribozyme were translated less efficiently than the polyadenylated reporters, as expected (data not 


\section{A F-LuC-CG5281}

- F-Luc / R-Luc activity 口 F-Luc / R-Luc mRNA

$\operatorname{Poly}(\mathrm{A})$
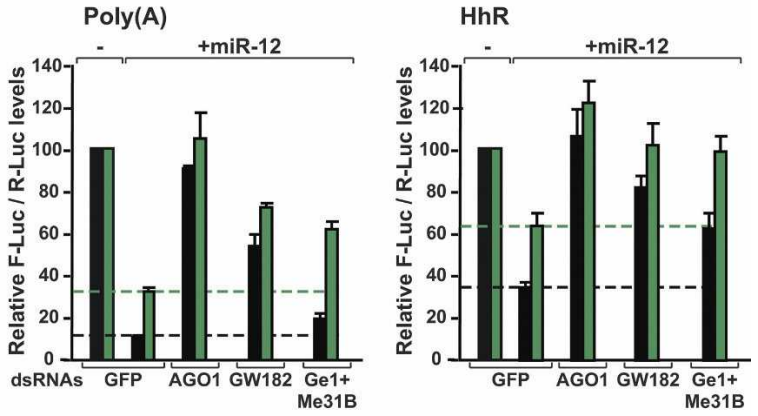

B F-Luc-CG7709

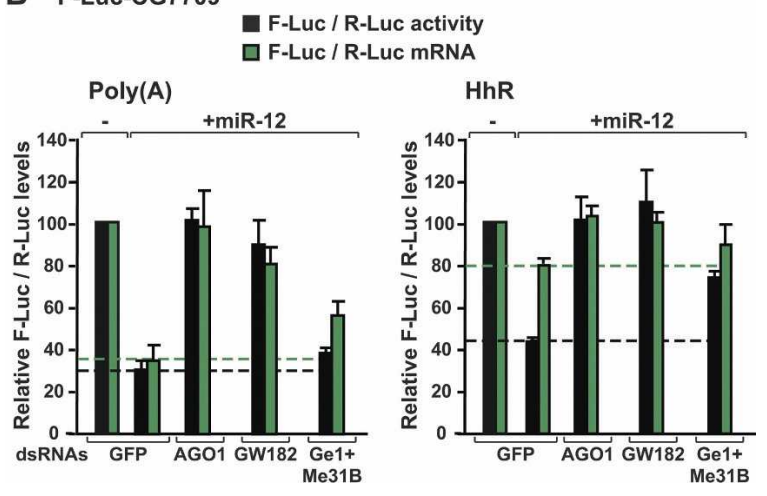

FIGURE 5. GW182 and decapping activators are required for silencing unadenylated mRNAs. $(A, B)$ S2 cells were treated with the indicated dsRNAs on days 0 and 4 . On day 6 , cells were cotransfected with a mixture of three plasmids: one expressing a Firefly luciferase (F-Luc) transcript containing the indicated 3' UTRs, another expressing the miR-12 primary transcript $(+)$ or the corresponding empty vector (-), and a third expressing Renilla luciferase (R-Luc). Samples were analyzed as described in Figure 4.

shown). In agreement with this, oligo(dT)-directed RNase $\mathrm{H}$ cleavage assays demonstrated that the reporters whose $3^{\prime}$ ends were generated by ribozyme cleavage were efficiently processed and did not have a poly(A) tail (Fig. 4C).

The ribozyme-containing reporters were silenced, albeit less efficiently than the corresponding mRNAs whose $3^{\prime}$ end was generated by polyadenylation (Fig. 4A,B). Moreover, the extent of mRNA degradation differed depending on the presence or absence of a poly(A) tail (Fig. 4A,B; also, see below).

The observation that mRNAs whose $3^{\prime}$ end is generated by ribozyme cleavage are silenced indicates that miRNAs can down-regulate the expression of targets that cannot adopt a closed-loop conformation. Thus, neither mRNA circularization nor a poly(A) tail are required for miRNA regulation.

\section{GW182 and decapping activators are required for silencing unadenylated mRNAs}

To ensure that a similar mechanism silenced both the reporters ending with a self-cleavable ribozyme and their polyadenylated counterparts, we tested whether silencing of these reporters required AGO1 or GW182. We found that depleting AGO1 or GW182 completely abrogated silencing of the ribozyme-containing reporters (Fig. 5A,B), as was shown for polyadenylated targets (Behm-Ansmant et al. 2006a,b; Eulalio et al. 2008b).

We also tested whether decapping activators are involved in the regulation of ribozyme-containing reporters. We observed that codepleting Ge-1 and Me31B suppressed mRNA decay triggered by miRNAs and partially restored

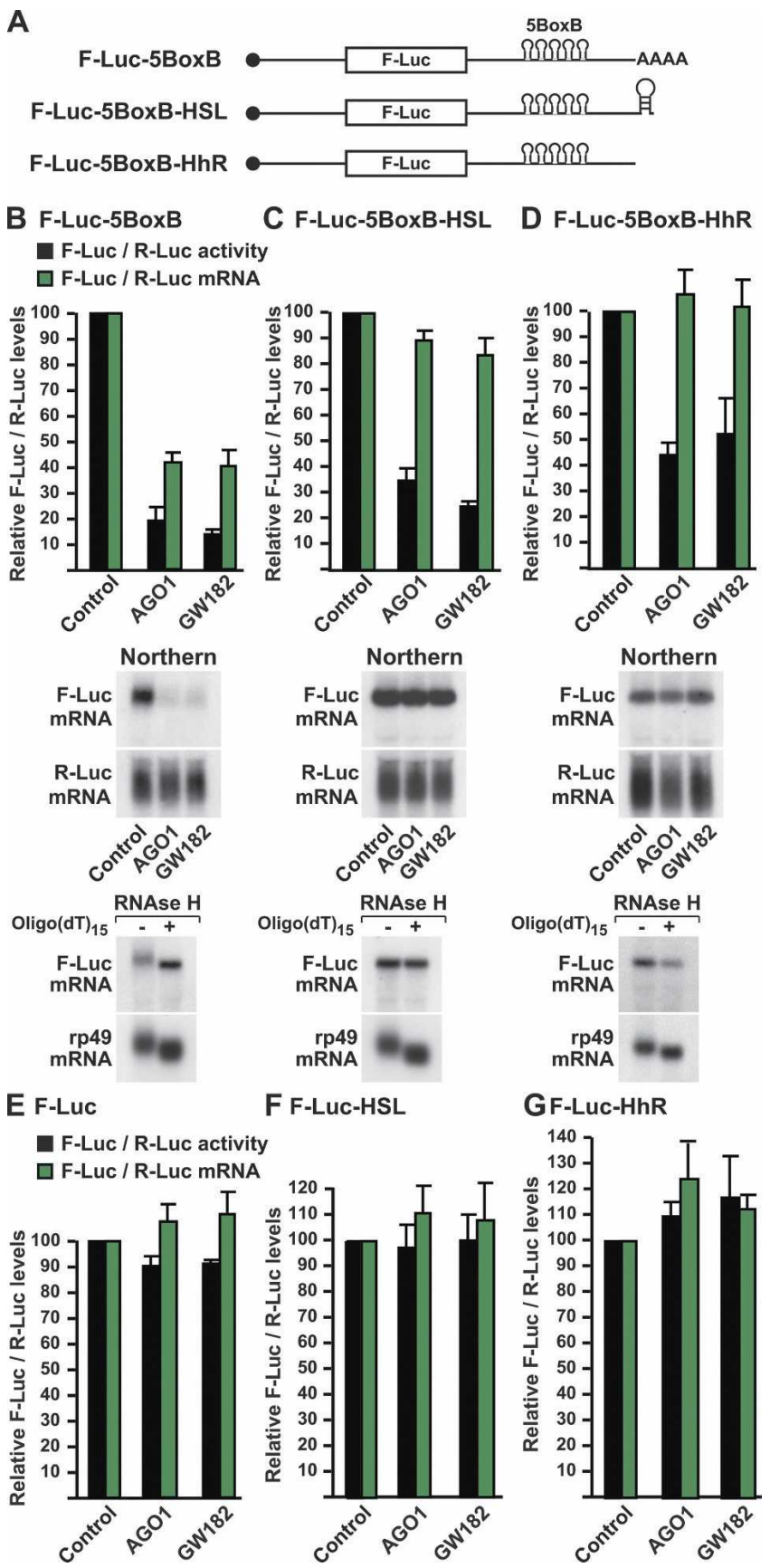

FIGURE 6. (Legend on next page) 
F-luc activity (Fig. 5A,B). Together, these results indicate that even when miRNA targets are unadenylated they are not only repressed at the translational level, but are also subject to miRNA-mediated decapping (and subsequent degradation).

\section{AGO1 and GW182 silence the expression of bound unadenylated mRNAs}

In previous studies, reporter mRNA could be silenced by artificially tethering an Argonaute protein or GW182 to the 3' UTR; the tethering bypasses the requirement for miRNA-binding sites in the 3' UTR (Pillai et al. 2004; Rehwinkel et al. 2005; Behm-Ansmant et al. 2006a,b; Eulalio et al. 2008b). Therefore, to confirm the results described above, we tested whether unadenylated reporters could be silenced by tethered AGO1 or GW182. For this assay, AGO1 and GW182 were N-terminally fused to a peptide derived from the $\mathrm{N}$ protein of bacteriophage- $\lambda(\lambda \mathrm{N}$ peptide); this peptide binds with high affinity to five phage$\lambda$ box B stem loops (5BoxB) that were inserted into the $3^{\prime}$ UTR of a firefly luciferase reporter mRNA. In addition to these binding sites, we replaced the cleavage and polyadenylation signal of the F-Luc-5BoxB reporter with the hammerhead ribozyme or the histone $\mathrm{H} 43^{\prime}$-terminal stem-loop structure (Fig. 6A, F-Luc-5BoxB-HhR, F-Luc5BoxB-HSL). The lack of a poly(A) tail for these reporters was confirmed by oligo(dT)-directed RNase $\mathrm{H}$ cleavage (Fig. 6B-D, bottom).

Expression of $\lambda \mathrm{N}$-HA-tagged AGO1 or GW182 reduced both luciferase activity and the abundance of the polyadenylated F-Luc-5BoxB mRNA, as shown before (Fig. 6B; Pillai et al. 2004; Rehwinkel et al. 2005; Behm-Ansmant et al. 2006a,b; Eulalio et al. 2008b). Translational repression, without changes in mRNA levels, was observed with the reporter ending with a histone stem-loop structure (Fig. 6C). Likewise, the ribozyme reporter was also translationally silenced, although less efficiently (Fig. 6D), in agreement with the results shown in Figure 4. The ex-

FIGURE 6. Deadenylation is not required for silencing by tethered AGO1 or GW182. (A) Schematic representation of the F-Luc-5BoxB reporters carrying $5 \mathrm{BoxB}$ elements inserted in their $3^{\prime}$ UTRs. The cleavage and polyadenylation signal of the F-Luc-5BoxB reporter was substituted either with a histone H4 3'-terminal stem-loop (HSL) or a self-cleavable hammerhead ribozyme (HhR). (B-G) S2 cells were transfected with a mixture of three plasmids: one expressing the FLuc-5BoxB reporters shown in $A$ or the corresponding reporters lacking the 5BoxB sequences (F-Luc), another expressing Renilla luciferase, and a third expressing the $\lambda \mathrm{N}-\mathrm{HA}$-peptide (Control) or $\lambda \mathrm{N}-\mathrm{HA}$ fusions of wild-type AGO1 or GW182, as indicated. For each reporter, firefly luciferase activity and mRNA levels were normalized to those of the Renilla and set to 100 in cells expressing the $\lambda \mathrm{N}-\mathrm{HA}$ peptide alone (Control). Mean values \pm standard deviations from three independent experiments are shown. Northern blot analysis of representative RNA samples is shown for the F-Luc-5BoxB reporters below the corresponding graphs. RNA samples shown in $B, C$, and $D$ (control lanes) were treated with RNase $\mathrm{H}$ in the absence or presence of oligo(dT) and analyzed by Northern blot. The endogenous rp49 mRNA served as a positive control for the RNase $\mathrm{H}$ treatment. pression of the corresponding reporters lacking the $5 \mathrm{BoxB}$ elements was not altered by overexpressing $\lambda \mathrm{N}-\mathrm{HA}-\mathrm{AGO} 1$ or $\lambda \mathrm{N}-\mathrm{HA}-\mathrm{GW} 182$ (Fig. $6 \mathrm{E}-\mathrm{G}$ ). Taken together, our results indicate that neither mRNA circularization nor a poly(A) tail are strictly required for silencing, and this remains so, irrespective of whether AGO1 or GW182 are artificially tethered to the reporter or recruited via miRNA-mRNA base-pairing interactions.

\section{miRNAs trigger degradation of mRNAs whose translation is blocked in cis}

Next we investigated whether miRNAs could trigger degradation of transcripts whose association with $40 \mathrm{~S}$ ribosomal subunits was blocked in cis. To this end, we inserted 5BoxB stem-loop structures $7 \mathrm{nt}$ downstream of the cap structure. As a control, 5BoxB stem-loop structures were also inserted $73 \mathrm{nt}$ downstream of the cap structure (Figs. 7, 8 ). The insertion of secondary structures very close to the $5^{\prime}$ cap (e.g., $12 \mathrm{nt}$ from the cap) was reported to prevent $40 \mathrm{~S}$ ribosomal subunits from binding, whereas the insertion distal from the cap (e.g., $72 \mathrm{nt}$ from the cap) interferes with ribosomal scanning (Kozak 1989). To stabilize these secondary structures, we coexpressed glutathione-S-transferase (GST) fused to the $\lambda \mathrm{N}$ peptide, which binds with high affinity to the $5 \mathrm{BoxB}$ elements.

We selected two previously characterized reporters for this analysis: F-Luc-par-6 and F-Luc-CG10011. For the F-Luc-par-6 reporter, we found the insertion of 5BoxB elements $7 \mathrm{nt}$ downstream of the cap structure reduced F-Luc activity by about 260-fold (Fig. 7B). A fourfold reduction in mRNA abundance was also observed (Fig. 7B), suggesting that the secondary structures destabilize the mRNA, most likely by interfering with eIF4E binding (note that other effects, such as interfering with binding of the nuclear cap-binding complex, cannot be excluded). Nevertheless, when F-Luc activities were normalized to mRNA levels, the insertion of the $5 \mathrm{BoxB}$ elements proximal to the cap structure reduced translation efficiency $\sim 60$-fold (Fig. 7C). Overexpressing $\lambda \mathrm{N}$-GST had no further inhibitory effect (Fig. 7B).

By comparison, inserting 5BoxB elements 73 nt downstream from the cap structure reduced F-Luc activity $\sim 40$ fold, without affecting mRNA levels (Fig. 7B,C). In the presence of $\lambda \mathrm{N}$-GST, translation was repressed $\sim 700$-fold (Fig. 7B,C). These results are consistent with the observation that scanning $40 \mathrm{~S}$ ribosomal subunits can disrupt some secondary structures (Kozak 1986, 1989), and proteins binding to these structures may enhance the translational block.

We next tested whether miRNAs could still trigger degradation of these reporters. We observed that miR-1 triggered degradation of the F-Luc-par-6 reporter, despite the translational block caused by inserting the 5BoxB elements at the two distinct positions within the $5^{\prime}$ UTR 
(Fig. 7D-G). Similarly, inserting 5BoxB elements in the $5^{\prime}$ UTR of the F-Luc-CG10011 reporter strongly inhibited translation, but did not prevent degradation by miR-12 (Fig. 8A-F). We conclude that miRNA-mediated mRNA degradation is not a secondary consequence of a primary effect of miRNAs on ribosomal subunit binding or function.

\section{DISCUSSION}

miRNAs elicit the deadenylation and subsequent degradation of target mRNAs (Wu and Belasco 2005; Behm-Ansmant et al. 2006a,b; Giraldez et al. 2006; Mishima et al. 2006; $\mathrm{Wu}$ et al. 2006; Eulalio et al. 2007, 2008b). However, it is unknown whether deadenylation is a general feature of miRNA-mediated degradation. The results presented in this manuscript indicate that deadenylation is a widespread effect of miRNA regulation that can occur prior to the association of $40 \mathrm{~S}$ ribosomal subunits. Although deadenylation is not absolutely required for silencing, when it does occur, the inhibitory effect of miRNAs is enhanced; thus, deadenylation strongly contributes to the extent to which a transcript is silenced.

\section{Translational repression and mRNA degradation contribute independently to silencing by miRNAs}

Previous studies reported that translational repression by miRNAs is not a consequence of reduced mRNA levels (Lee et al. 1993; Wightman et al. 1993; Moss et al. 1997; Olsen and Ambros 1999; Pillai et al. 2005; Bhattacharyya et al. 2006; Maroney et al. 2006; Nottrott et al. 2006; Petersen et al. 2006; Wang et al. 2006; Mathonnet et al. 2007; Thermann and Hentze 2007). Furthermore, for targets that are degraded, translational repression is observed even when degradation is prevented by depleting components of the deadenylase complex (Behm-Ansmant et al. 2006a,b). Together, these observations led to the hypothesis that the primary effect of miRNAs is to inhibit translation, with mRNA degradation being a consequence of this primary effect.

More recently, however, several studies have shown that miRNAs can trigger mRNA degradation in the absence of active translation, indicating that mRNA decay is not a mere consequence of the translational block caused by miRNAs. Indeed, a subset of miRNA targets are degraded in the presence of cycloheximide (Eulalio et al. 2007; Wakiyama et al. 2007). Moreover, in human cells and zebrafish embryos, nontranslatable miRNA targets (e.g., containing a strong stem-loop in the 5' UTR or an Apppcap structure) were nevertheless deadenylated and degraded in the presence of cognate miRNAs (Mishima et al. 2006; Wu et al. 2006).

Our results with reporters carrying $5 \mathrm{BoxB}$ elements inserted $73 \mathrm{nt}$ downstream of the cap structure confirm those reported by $\mathrm{Wu}$ et al. (2006) and show that miRNA- mediated mRNA degradation occurs even when ribosomal scanning is blocked. These observations are extended by our experiments showing that miRNAs trigger mRNA degradation also when $40 \mathrm{~S}$ ribosomal subunit binding is prevented by 5 BoxB elements inserted $7 \mathrm{nt}$ downstream of the cap structure. In agreement with this, Mishima et al. (2006) showed that when translation initiation was inhibited in cis by incorporating an Appp-cap structure, miRNA targets were still deadenylated and degraded in zebrafish embryos. These observations show that miRNAs can trigger deadenylation and subsequent decay at a step prior to the association of $40 \mathrm{~S}$ ribosomal subunits.

Moreover, these observations also show that the effects of miRNAs on mRNA translation and degradation can be

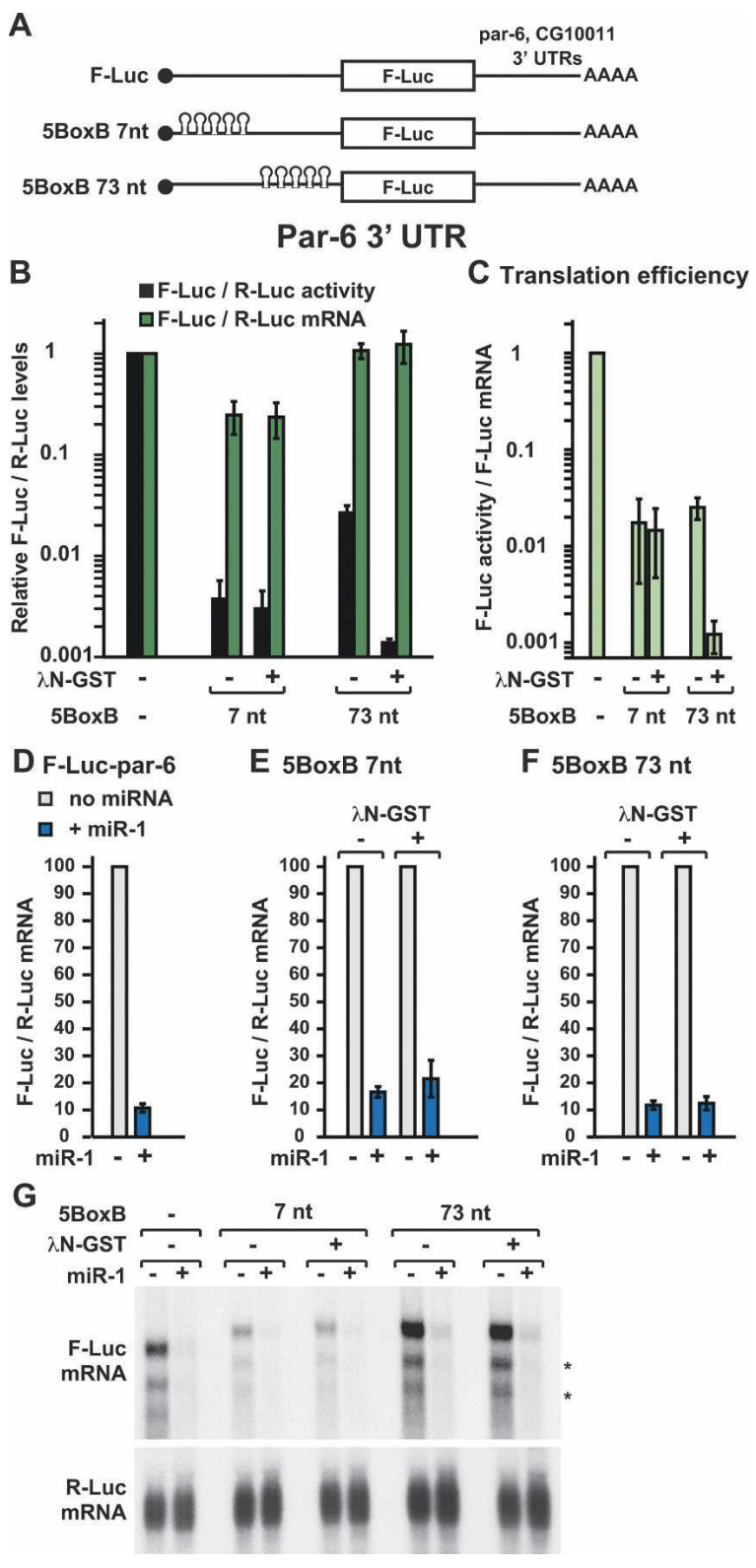

FIGURE 7. (Legend on next page) 
uncoupled. Clearly, under normal conditions both effects contribute to the extent of silencing and influence each other. Indeed, by promoting deadenylation of target mRNAs, miRNAs can more effectively inhibit translation. Whether or not miRNAs trigger degradation is likely to depend on the complement of specific proteins associated with a given target and/or on some specific features of the miRNA-binding site and its RNA context (Behm-Ansmant et al. 2006a,b; Alemán et al. 2007; Eulalio et al. 2007; Grimson et al. 2007).

\section{Mechanism of miRNA-mediated gene silencing}

An important conclusion from this study is that miRNAs increase the accessibility of general mRNA degradation enzymes to the mRNA $5^{\prime}$ cap structure and the poly(A) tail, even when binding of $40 \mathrm{~S}$ ribosomal subunits is prevented in cis. These findings indicate that miRNAs trigger mRNA decay by inducing changes in mRNP composition and/or structure, rather than by directly interfering with binding and function of ribosomal subunits. This raises the question: what is the primary effect of miRNAs?

Wakiyama et al. (2007) proposed that by promoting deadenylation, miRNAs interfere with the formation of the mRNA closed-loop conformation. This conformation is thought to enhance translation and is achieved through the interactions between the cytoplasmic poly(A)-binding protein (PABPC1) bound to the mRNA poly(A) tail and the translation initiation factor $4 \mathrm{G}$ (eIF4G) bound to the $5^{\prime}$ cap structure (Wakiyama et al. 2007, and references therein).

FIGURE 7. Uncoupling mRNA degradation from translation. (A) Schematic representation of the F-Luc reporters with 5BoxB elements inserted at position 7 or 73 of their $5^{\prime}$ UTRs. The initiation codon is located at position 105. $(B, C) \mathrm{S} 2$ cells were transfected with a mixture of three plasmids: one expressing one of the F-Luc-par-6 reporters shown in $A$, another expressing Renilla luciferase (R-Luc), and a third expressing a $\lambda \mathrm{N}$-HA fusion of GST (Glutathione-S-transferase), as indicated. F-Luc activity and mRNA levels were normalized to those of the Renilla luciferase and set to 1 for the reporter lacking the 5BoxB elements. In $C$, the normalized levels of F-Luc activity were divided by the normalized levels of F-Luc mRNA for each reporter. Mean values \pm standard deviations from three independent experiments are shown. Note that in $B$ and $C$ the scale on the $y$-axis is logarithmic. $(D-G)$ S2 cells were cotransfected with a mixture of plasmids expressing the F-Luc reporters shown in $A$, a plasmid expressing the miR-1 primary transcript (+; blue bars) or the corresponding empty vector ( - ; gray bars), plus a plasmid expressing Renilla luciferase (RLuc). A plasmid expressing a $\lambda \mathrm{N}-\mathrm{HA}$ fusion of GST was included in the transfection mixtures as indicated. F-Luc mRNA levels were normalized to that of the Renilla luciferase and set to 100 in cells transfected with the empty vector (i.e., in the absence of the miRNA; gray bars) for each reporter. Mean values \pm standard deviations from three independent experiments are shown. $(G)$ Northern blot analysis of representative RNA samples shown in $D-F$. Asterisks indicate the position of transcripts generated by alternative polyadenylation sites in the par-6 3' UTR. These alternative polyadenylation sites are located downstream of the predicted miR-1 binding sites.

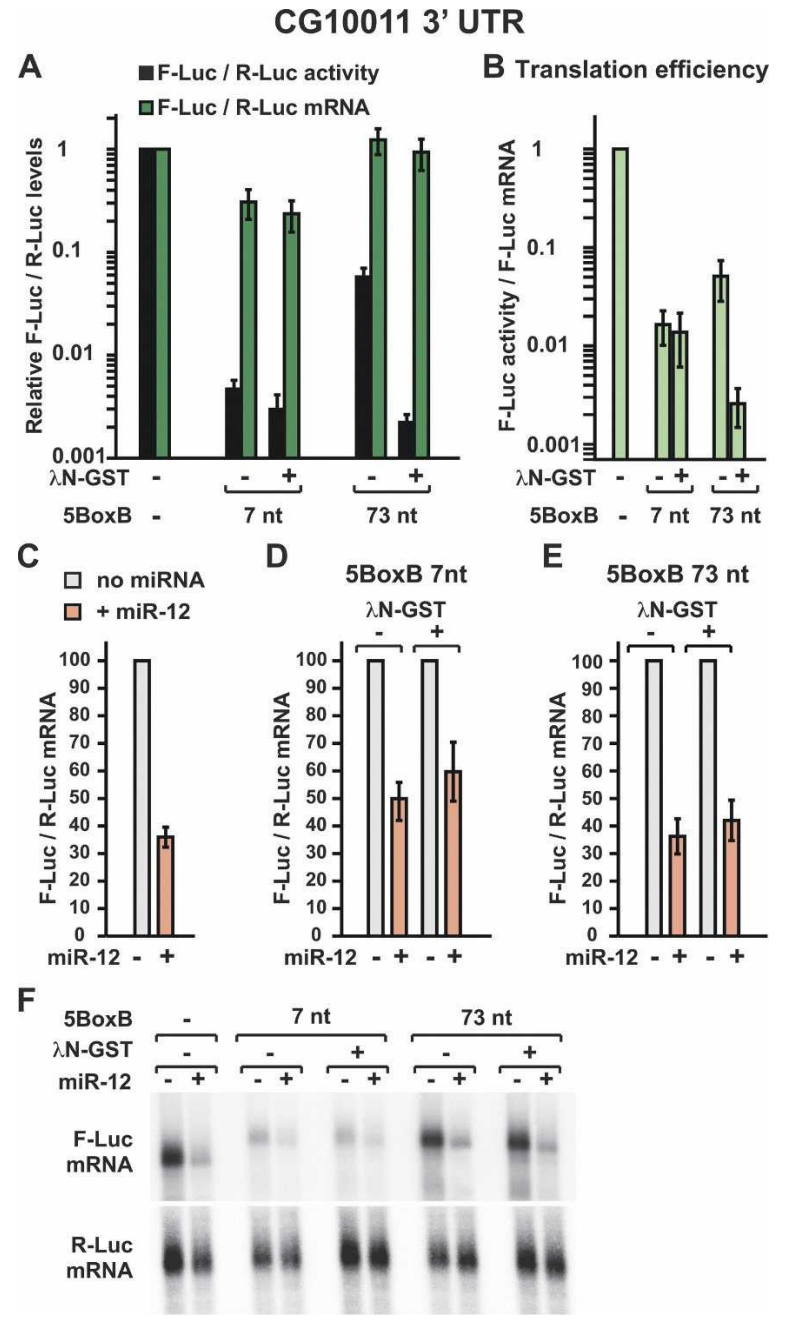

FIGURE 8. Uncoupling mRNA degradation from translation. $(A-F)$ Experiments similar to those described in Figure 7 were performed with the F-Luc-CG10011 reporters shown in Figure 7A. Samples were analyzed as described in Figure 7.

Although this model could explain both the translational repression and mRNA degradation caused by miRNAs, it is not consistent with the observation that miRNAs also silence transcripts that cannot circularize (i.e., mRNAs whose $3^{\prime}$ end is generated by ribozyme cleavage). Furthermore, our results show that a poly(A) tail is not specifically required for silencing.

Another model of silencing is that Argonaute proteins compete with eIF4E for binding to the $5^{\prime}$ cap structure (Kiriakidou et al. 2007). This model could also account for both miRNA-mediated translational repression and accelerated mRNA degradation. However, the molecular details of the underlying mechanism remain to be elucidated. The cap-binding activity of Argonaute proteins was shown to be mediated by two conserved phenylalanines located in the mid domain of these proteins (Kiriakidou et al. 2007). We recently showed that these phenylalanines are also required 
for Argonaute proteins to interact with GW182 and miRNAs (Eulalio et al. 2008b), suggesting that they may have a structural role that is unrelated to cap binding. Nevertheless, it is still possible that additional domains in the Argonaute proteins or in other RISC components mediate cap binding. Thus, although our results are consistent with models in which miRNAs interfere with the function of the $5^{\prime}$ cap structure and/or of cap-binding proteins, further structural and biochemical studies will be needed to unravel the molecular mechanism of such interference.

\section{MATERIALS AND METHODS}

\section{RNA isolation and genome-wide expression analysis}

High-density oligonucleotide microarrays (Affymetrix D. melanogaster array 2) covering more than 18,500 transcripts from $D$. melanogaster were used. Total RNA was isolated using Trifast Reagent (PeqLab). To reduce potential variations in sample preparation, two RNA preparations were isolated from a single knockdown experiment. To minimize differences in knockdown efficiencies, these preparations were pooled with the equivalent preparations isolated from an independent knockdown. These pools of four RNA preparations from two independent knockdowns are referred to as RNA samples.

Preparation of biotinylated targets, hybridizations, and data acquisition were according to standard Affymetrix procedures. All experiments were normalized using an intensity-dependent normalization scheme (Lowess). Data were analyzed as described by Rehwinkel et al. (2006). The microarray data have been submitted to the ArrayExpress database at EBI under accession number E-MEXP-1713.

\section{DNA constructs}

Luciferase reporters were described before (Rehwinkel et al. 2005; Behm-Ansmant et al. 2006a; Eulalio et al. 2007). Additional wildtype $3^{\prime}$ UTRs of predicted miRNA targets were amplified by PCR from a $D$. melanogaster S2 cell genomic DNA library and cloned downstream of the firefly luciferase coding region, between the EcoRI and SalI sites of plasmid pAc5.1C-F-Luc. All 3' UTRs contained the natural 3 ' polyadenylation signals. Renilla luciferase cloned between the EcoRI and XhoI sites of vector pAc5.1A (Invitrogen) served as a transfection control. For expression of miRNAs, a fragment of $\sim 400$ nucleotides encompassing the miRNA gene was amplified from genomic DNA and cloned in vector pAc5.1A downstream of the actin 5C promoter.

To generate reporters with a hammerhead ribozyme, 3' UTRs of $D$. melanogaster genes were amplified by PCR using $3^{\prime}$ oligos designed to exclude the natural polyadenylation sequences. These oligos contained AvrII, SacII, and SalI restriction sites. The amplified 3' UTRs were then cloned downstream of the firefly luciferase coding region, between the EcoRI and SalI sites of plasmid pAc5.1C-F-Luc. This insertion deletes the polyadenylation site provided by the vector.

The hammerhead ribozyme was amplified by PCR using plasmid TDH-GFP-RZ as template (Dower et al. 2004) and cloned into the unique AvrII-SacII sites of the reporters. The hammerhead ribozyme was also inserted between the BamHI and SalI sites of the FLuc-5BoxB reporter (Rehwinkel et al. 2005). The histone H4 stem-loop structure was amplified by PCR using as template D. melanogaster histone $\mathrm{H} 4$ minigene (Adamson and Price 2003), and inserted between the BamHI and SalI sites of the FLuc-5BoxB reporter (Rehwinkel et al. 2005).

To inhibit translation of the reporters in cis, a cDNA fragment encompassing 5 BoxB elements was amplified by PCR using the F-Luc-5BoxB reporter as a template (Rehwinkel et al. 2005) and cloned into unique HindIII sites introduced by mutagenesis at different positions within the 5' UTR of the F-Luc-CG10011 and F-Luc-par-6 reporters.

\section{Cell transfections and RNA interference}

All transfections were performed with Effectene (QIAGEN). When transfections were performed in 6-well plates, the transfection mixtures contained $0.1 \mu \mathrm{g}$ of firefly luciferase reporter plasmid, $0.4 \mu \mathrm{g}$ of the Renilla transfection control, and $0.5 \mu \mathrm{g}$ of plasmids expressing miRNA primary transcripts. For the $\lambda \mathrm{N}$-tethering assay, the following plasmids were cotransfected: $0.1 \mu \mathrm{g}$ of reporter plasmid (F-Luc-5BoxB or F-Luc), $0.4 \mu \mathrm{g}$ of pAc5.1-RLuc as transfection control, and $0.01 \mu \mathrm{g}$ of plasmids expressing $\lambda \mathrm{N}-\mathrm{HA}$-protein fusions. Cells were collected $3 \mathrm{~d}$ after transfection. Luciferase activity was measured using the Dual-Luciferase reporter assay system (Promega). RNA interference and Northern blotting were performed as described before (Rehwinkel et al. 2005). RNase H (USB) digestion using a $(\mathrm{dT})_{15}$ oligonucleotide was performed according to the manufacturer's instructions.

\section{SUPPLEMENTAL DATA}

Supplemental material can be found at http://www.rnajournal.org.

\section{ACKNOWLEDGMENTS}

We are grateful to S.M. Cohen for providing miRNA expression vectors and the par-6 reporter. This study was supported by the Max Planck Society through a grant from the Deutsche Forschungsgemeinschaft (DFG, FOR855), and by the Sixth Framework Programme of the European Commission through the SIROCCO Integrated Project LSHG-CT-2006-037900. T.N. is the recipient of a fellowship from Schering.

Received October 2, 2008; accepted October 20, 2008.

\section{REFERENCES}

Adamson, T.E. and Price, D.H. 2003. Cotranscriptional processing of D. melanogaster histone mRNAs. Mol. Cell. Biol. 23: 4046-4055.

Alemán, L.M., Doench, J., and Sharp, P.A. 2007. Comparison of siRNA-induced off-target RNA and protein effects. RNA 13: 385395.

Bagga, S., Bracht, J., Hunter, S., Massirer, K., Holtz, J., Eachus, R., and Pasquinelli, A.E. 2005. Regulation by let-7 and lin-4 miRNAs results in target mRNA degradation. Cell 122: 553-563.

Baek, D., Villén, J., Shin, C., Camargo, F.D., Gygi, S.P., and Bartel, D.P. 2008. The impact of microRNAs on protein output. Nature 455: 64-71. 
Behm-Ansmant, I., Rehwinkel, J., Doerks, T., Stark, A., Bork, P., and Izaurralde, E. 2006a. mRNA degradation by miRNAs and GW182 requires both CCR4:NOT deadenylase and DCP1:DCP2 decapping complexes. Genes \& Dev. 20: 1885-1898.

Behm-Ansmant, I., Rehwinkel, J., and Izaurralde, E. 2006b. MicroRNAs silence gene expression by repressing protein expression and/or by promoting mRNA decay. Cold Spring Harb. Symp. Quant. Biol. 71: 523-530.

Bhattacharyya, S.N., Habermacher, R., Martine, U., Closs, E.I., and Filipowicz, W. 2006. Relief of microRNA-mediated translational repression in human cells subjected to stress. Cell 125: 11111124.

Bushati, N. and Cohen, S.M. 2007. microRNA functions. Annu. Rev. Cell Dev. Biol. 23: 175-205.

Chendrimada, T.P., Finn, K.J., Ji, X., Baillat, D., Gregory, R.I., Liebhaber, S.A., Pasquinelli, A.E., and Shiekhattar, R. 2007. MicroRNA silencing through RISC recruitment of eIF6. Nature 447: 823-828.

Chu, C.Y. and Rana, T.M. 2006. Translation repression in human cells by microRNA-induced gene silencing requires RCK/p54. PLoS Biol. 4: e210. doi: 10.1371/journal.pbio.0040210.

Ding, L., Spencer, A., Morita, K., and Han, M. 2005. The developmental timing regulator AIN-1 interacts with miRISCs and may target the argonaute protein ALG-1 to cytoplasmic P bodies in $C$. elegans. Mol. Cell 19: 437-447.

Dower, K., Kuperwasser, N., Merrikh, H., and Rosbash, M. 2004. A synthetic A tail rescues $S$. cerevisiae nuclear accumulation of a ribozyme-terminated transcript. RNA 10: 1888-1899.

El-Shami, M., Pontier, D., Lahmy, S., Braun, L., Picart, C., Vega, D. Hakimi, M.A., Jacobsen, S.E., Cooke, R., and Lagrange, T. 2007. Reiterated WG/GW motifs form functionally and evolutionarily conserved ARGONAUTE-binding platforms in RNAi-related components. Genes \& Dev. 21: 2539-2544.

Eulalio, A., Rehwinkel, J., Stricker, M., Huntzinger, E., Yang, S.F., Doerks, T., Dorner, S., Bork, P., Boutros, M., and Izaurralde, E. 2007. Target-specific requirements for enhancers of decapping in miRNA-mediated gene silencing. Genes \& Dev. 21: 2558-2570.

Eulalio, A., Huntzinger, E., and Izaurralde, E. 2008a. Getting to the root of miRNA-mediated gene silencing. Cell 132: 9-14.

Eulalio, A., Huntzinger, E., and Izaurralde, E. 2008b. GW182 interaction with Argonaute is essential for miRNA-mediated translational repression and mRNA decay. Nat. Struct. Mol. Biol. 15: 346-353.

Giraldez, A.J., Mishima, Y., Rihel, J., Grocock, R.J., Van Dongen, S., Inoue, K., Enright, A.J., and Schier, A.F. 2006. Zebrafish MiR-430 promotes deadenylation and clearance of maternal mRNAs. Science 312: 75-79.

Gorgoni, B., Andrews, S., Schaller, A., Schümperli, D., Gray, N.K., and Müller, B. 2005. The stem-loop binding protein stimulates histone translation at an early step in the initiation pathway. RNA 11: 1030-1042.

Grimson, A., Farh, K.K., Johnston, W.K., Garrett-Engele, P., Lim, L.P., and Bartel, D.P. 2007. MicroRNA targeting specificity in mammals: Determinants beyond seed pairing. Mol. Cell 27: 91-105.

Humphreys, D.T., Westman, B.J., Martin, D.I., and Preiss, T. 2005. MicroRNAs control translation initiation by inhibiting eukaryotic initiation factor 4E/cap and poly(A) tail function. Proc. Natl. Acad. Sci. 102: 16961-16966.

Jakymiw, A., Lian, S., Eystathioy, T., Li, S., Satoh, M., Hamel, J.C., Fritzler, M.J., and Chan, E.K. 2005. Disruption of GW bodies impairs mammalian RNA interference. Nat. Cell Biol. 7: 12671274.

Kiriakidou, M., Tan, G.S., Lamprinaki, S., De Planell-Saguer, M., Nelson, P.T., and Mourelatos, Z. 2007. An mRNA m(7)G cap binding-like motif within human Ago2 represses translation. Cell 129: $1141-1151$.

Kozak, M. 1986. Influences of mRNA secondary structure on initiation by eukaryotic ribosomes. Proc. Natl. Acad. Sci. 83: 2850-2854.
Kozak, M. 1989. Circumstances and mechanisms of inhibition of translation by secondary structure in eucaryotic mRNAs. Mol. Cell. Biol. 9: 5134-5142.

Krützfeldt, J., Rajewsky, N., Braich, R., Rajeev, K.G., Tuschl, T., Manoharan, M., and Stoffel, M. 2005. Silencing of microRNAs in vivo with "antagomirs." Nature 438: 685-689.

Lee, R.C., Feinbaum, R.L., and Ambros, V. 1993. The C. elegans heterochronic gene lin-4 encodes small RNAs with antisense complementarity to lin-14. Cell 75: 843-854.

Lim, L.P., Lau, N.C., Garrett-Engele, P., Grimson, A., Schelter, J.M., Castle, J., Bartel, D.P., Linsley, P.S., and Johnson, J.M. 2005. Microarray analysis shows that some microRNAs downregulate large numbers of target mRNAs. Nature 433: 769-773.

Ling, J., Morley, S.J., Pain, V.M., Marzluff, W.F., and Gallie, D.R. 2002. The histone $3^{\prime}$-terminal stem-loop-binding protein enhances translation through a functional and physical interaction with eukaryotic initiation factor 4G (eIF4G) and eIF3. Mol. Cell. Biol. 22: 7853-7867.

Liu, J., Rivas, F.V., Wohlschlegel, J., Yates III, J.R., Parker, R., and Hannon, G.J. 2005. A role for the P-body component GW182 in microRNA function. Nat. Cell Biol. 7: 1261-1266.

Maroney, P.A., Yu, Y., Fisher, J., and Nilsen, T.W. 2006. Evidence that microRNAs are associated with translating messenger RNAs in human cells. Nat. Struct. Mol. Biol. 13: 1102-1107.

Mathonnet, G., Fabian, M.R., Svitkin, Y.V., Parsyan, A., Huck, L., Murata, T., Biffo, S., Merrick, W.C., Darzynkiewicz, E., Pillai, R.S., et al. 2007. MicroRNA inhibition of translation initiation in vitro by targeting the cap-binding complex eIF4F. Science 317: 17641767.

Meister, G., Landthaler, M., Peters, L., Chen, P.Y., Urlaub, H., Luhrmann, R., and Tuschl, T. 2005. Identification of novel argonaute-associated proteins. Curr. Biol. 15: 2149-2155.

Mishima, Y., Giraldez, A.J., Takeda, Y., Fujiwara, T., Sakamoto, H., Schier, A.F., and Inoue, K. 2006. Differential regulation of germline mRNAs in soma and germ cells by zebrafish miR-430. Curr. Biol. 16: 2135-2142.

Moss, E.G., Lee, R.C., and Ambros, V. 1997. The cold shock domain protein LIN-28 controls developmental timing in C. elegans and is regulated by the lin-4 RNA. Cell 88: 637-646.

Nilsen, T.W. 2007. Mechanisms of microRNA-mediated gene regulation in animal cells. Trends Genet. 23: 243-249.

Nottrott, S., Simard, M.J., and Richter, J.D. 2006. Human let-7a miRNA blocks protein production on actively translating polyribosomes. Nat. Struct. Mol. Biol. 13: 1108-1114.

Olsen, P.H. and Ambros, V. 1999. The lin-4 regulatory RNA controls developmental timing in Caenorhabditis elegans by blocking LIN14 protein synthesis after the initiation of translation. Dev. Biol. 216: 671-680.

Petersen, C.P., Bordeleau, M.E., Pelletier, J., and Sharp, P.A. 2006. Short RNAs repress translation after initiation in mammalian cells. Mol. Cell 21: 533-542.

Pillai, R.S., Artus, C.G., and Filipowicz, W. 2004. Tethering of human Ago proteins to mRNA mimics the miRNA-mediated repression of protein synthesis. RNA 10: 1518-1525.

Pillai, R.S., Bhattacharyya, S.N., Artus, C.G., Zoller, T., Cougot, N., Basyuk, E., Bertrand, E., and Filipowicz, W. 2005. Inhibition of translational initiation by Let-7 microRNA in human cells. Science 309: 1573-1576.

Rehwinkel, J., Behm-Ansmant, I., Gatfield, D., and Izaurralde, E. 2005. A crucial role for GW182 and the DCP1:DCP2 decapping complex in miRNA-mediated gene silencing. RNA 11: 16401647.

Rehwinkel, J., Natalin, P., Stark, A., Brennecke, J., Cohen, S.M., and Izaurralde, E. 2006. Genome-wide analysis of mRNAs regulated by Drosha and Argonaute proteins in Drosophila melanogaster. Mol. Cell. Biol. 26: 2965-2975.

Selbach, M., Schwanhäusser, B., Thierfelder, N., Fang, Z., Khanin, R., and Rajewsky, N. 2008. Widespread changes in protein synthesis induced by microRNAs. Nature 455: 58-63. 
Schmitter, D., Filkowski, J., Sewer, A., Pillai, R.S., Oakeley, E.J., Zavolan, M., Svoboda, P., and Filipowicz, W. 2006. Effects of Dicer and Argonaute down-regulation on mRNA levels in human HEK293 cells. Nucleic Acids Res. 34: 4801-4815.

Temme, C., Zaessinger, S., Meyer, S., Simonelig, M., and Wahle, E. 2004. A complex containing the CCR4 and CAF1 proteins is involved in mRNA deadenylation in Drosophila. EMBO J. 23: 2862-2871.

Thermann, R. and Hentze, M.W. 2007. Drosophila miR2 induces pseudo-polysomes and inhibits translation initiation. Nature 447: 875-878.

Till, S., Lejeune, E., Thermann, R., Bortfeld, M., Hothorn, M., Enderle, D., Heinrich, C., Hentze, M.W., and Ladurner, A.G. 2007. A conserved motif in Argonaute-interacting proteins mediates functional interactions through the Argonaute PIWI domain. Nat. Struct. Mol. Biol. 14: 897-903.

Wakiyama, M., Takimoto, K., Ohara, O., and Yokoyama, S. 2007. Let7 microRNA-mediated mRNA deadenylation and translational repression in a mammalian cell-free system. Genes \& Dev. 21: $1857-1862$

Wang, B., Love, T.M., Call, M.E., Doench, J.G., and Novina, C.D. 2006. Recapitulation of short RNA-directed translational gene silencing in vitro. Mol. Cell 22: 553-560.

Wightman, B., Ha, I., and Ruvkun, G. 1993. Posttranscriptional regulation of the heterochronic gene lin-14 by lin- 4 mediates temporal pattern formation in C. elegans. Cell 75: 855-862.

$\mathrm{Wu}, \mathrm{L}$. and Belasco, J.G. 2005. Micro-RNA regulation of the mammalian lin-28 gene during neuronal differentiation of embryonal carcinoma cells. Mol. Cell. Biol. 25: 9198-9208.

Wu, L., Fan, J., and Belasco, J.G. 2006. MicroRNAs direct rapid deadenylation of mRNA. Proc. Natl. Acad. Sci. 103: 4034-4039.

Zhang, L., Ding, L., Cheung, T.H., Dong, M.-Q., Chen, J., Sewell, A.K., Liu, X., Yates, J.R., and Han, M. 2007. Systematic identification of $C$. elegans miRISC proteins, miRNAs, and mRNA targets by their interactions with GW182 proteins AIN-1 and AIN2. Mol. Cell 28: 598-613. 

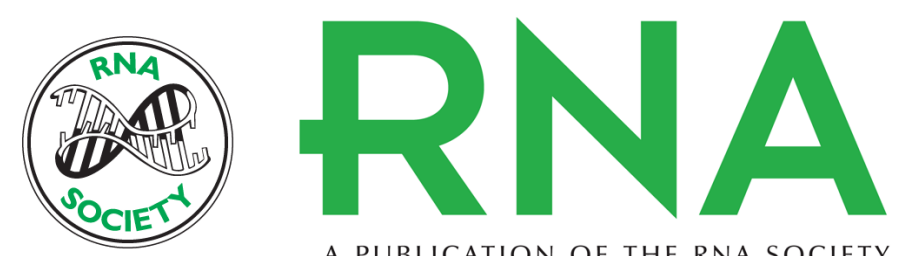

A PUBLICATION OF THE RNA SOCIETY

\section{Deadenylation is a widespread effect of miRNA regulation}

Ana Eulalio, Eric Huntzinger, Tadashi Nishihara, et al.

RNA 2009 15: 21-32 originally published online November 24, 2008

Access the most recent version at doi:10.1261/rna.1399509

Supplemental http://rnajournal.cshlp.org/content/suppl/2008/11/24/rna.1399509.DC1

References This article cites 53 articles, 22 of which can be accessed free at: http://rnajournal.cshlp.org/content/15/1/21.full.html\#ref-list-1

Open Access Freely available online through the RNA Open Access option.

License Freely available online through the open access option.

Email Alerting Receive free email alerts when new articles cite this article - sign up in the box at the Service top right corner of the article or click here.

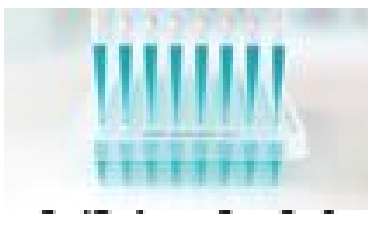

Providing Precise Solutions for your research.

To subscribe to $R N A$ go to:

http://rnajournal.cshlp.org/subscriptions 